\title{
Catalytic Macrocyclization Strategies Using Continuous Flow: Formal Total Synthesis of Ivorenolide A.
}

Mylène de Léséleuc, Éric Godin, Shawn Parisien-Collette, Alexandre Lévesque and Shawn K. Collins*

Département de Chimie, Centre for Green Chemistry and Catalysis, Université de Montréal, CP 6128 Station Downtown, Montréal, Québec, CANADA H3C 3J7

\section{SUPPORTING INFORMATION}

TABLE OF CONTENTS:

OPTIMIZATION OF A Z-SELECTIVE CROSS METATHESIS SPECTRAL DATA FOR KNOWN COMPOUNDS SPECTRAL DATA FOR NEW COMPOUNDS

S6




\section{OPTIMIZATION OF A Z-SELECTIVE CROSS METATHESIS}

Table S1 Optimization of a Z-selective cross metathesis to prepare racemic 13.

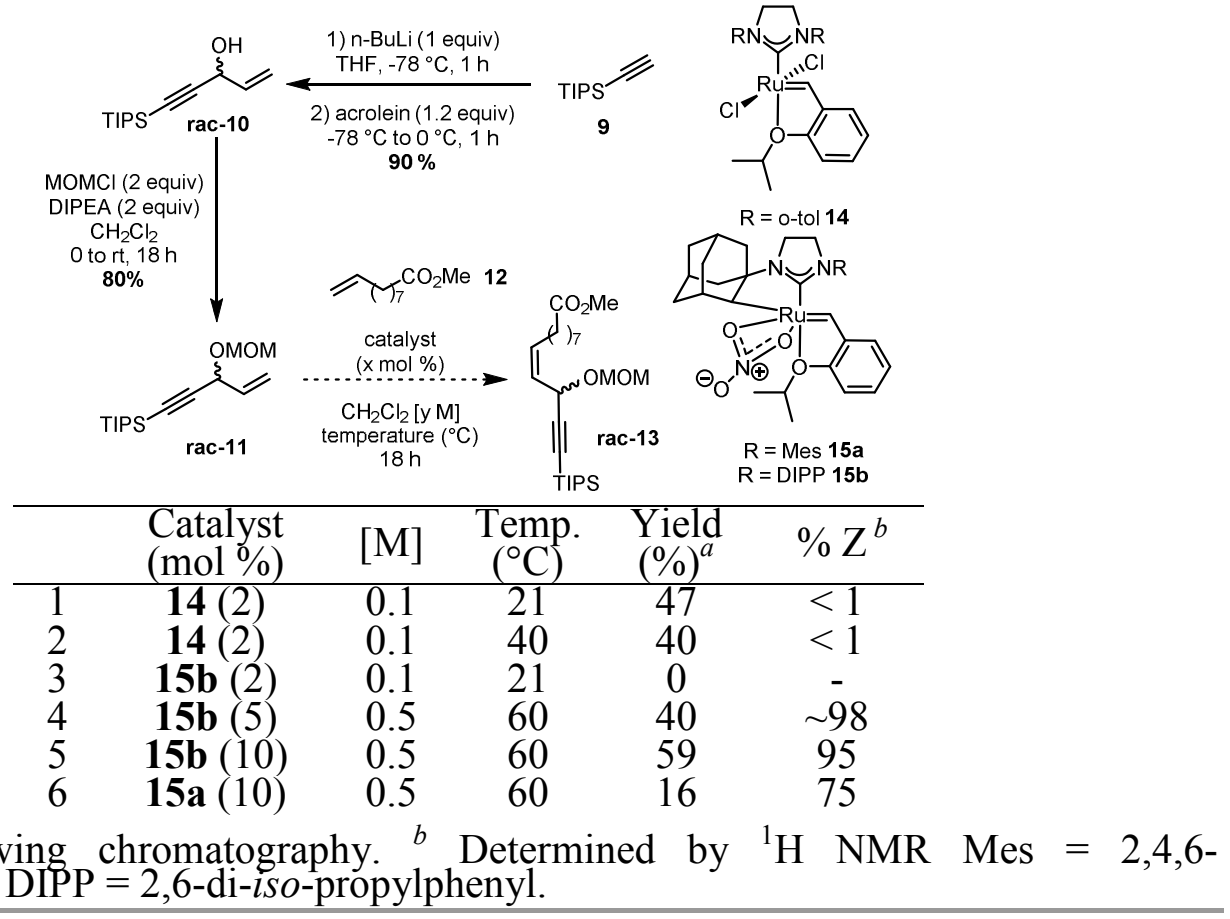




\section{SPECTRAL DATA FOR KNOWN COMPOUNDS}

\section{Molecule 5}

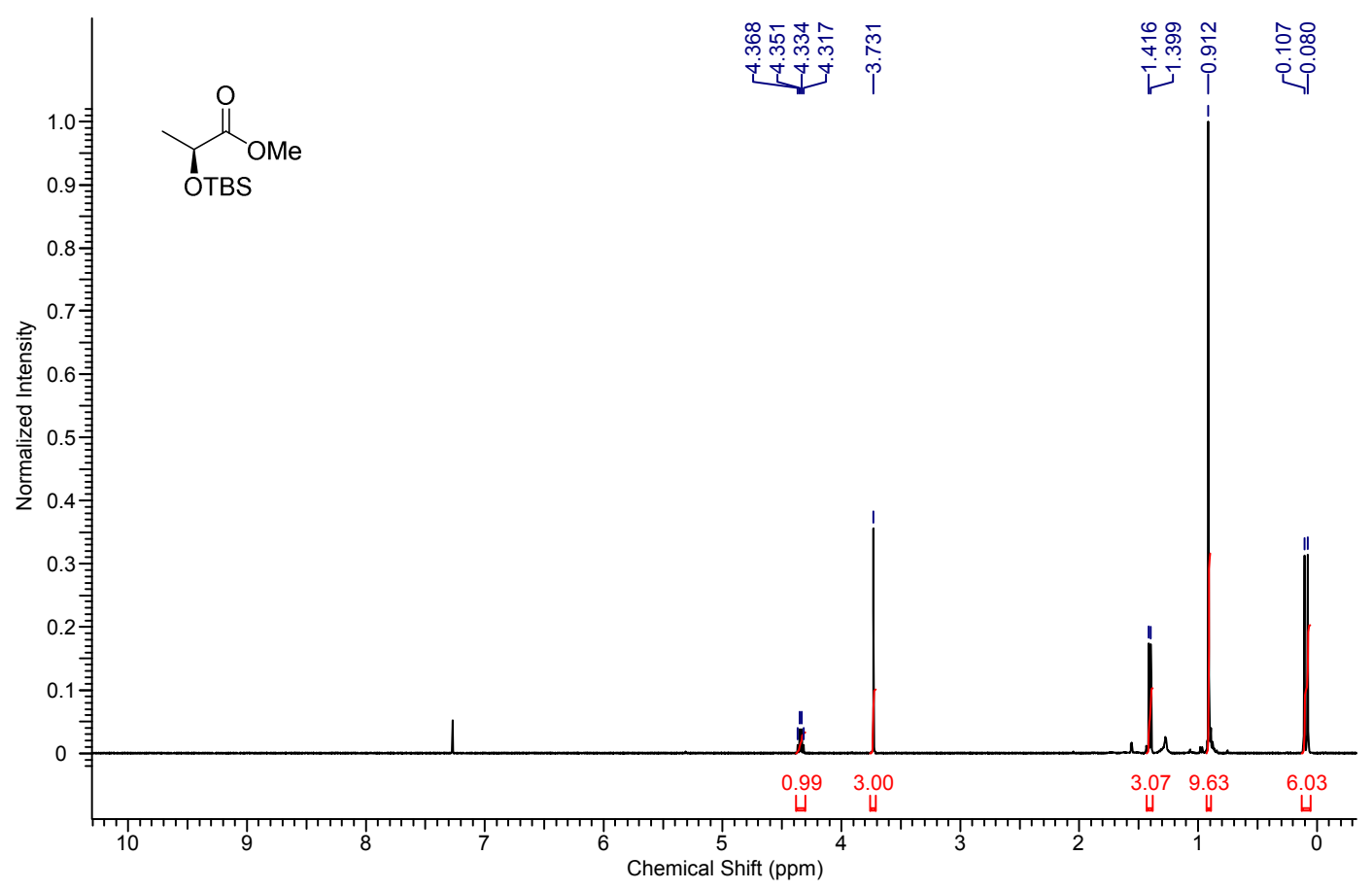

\section{Molecule 6}

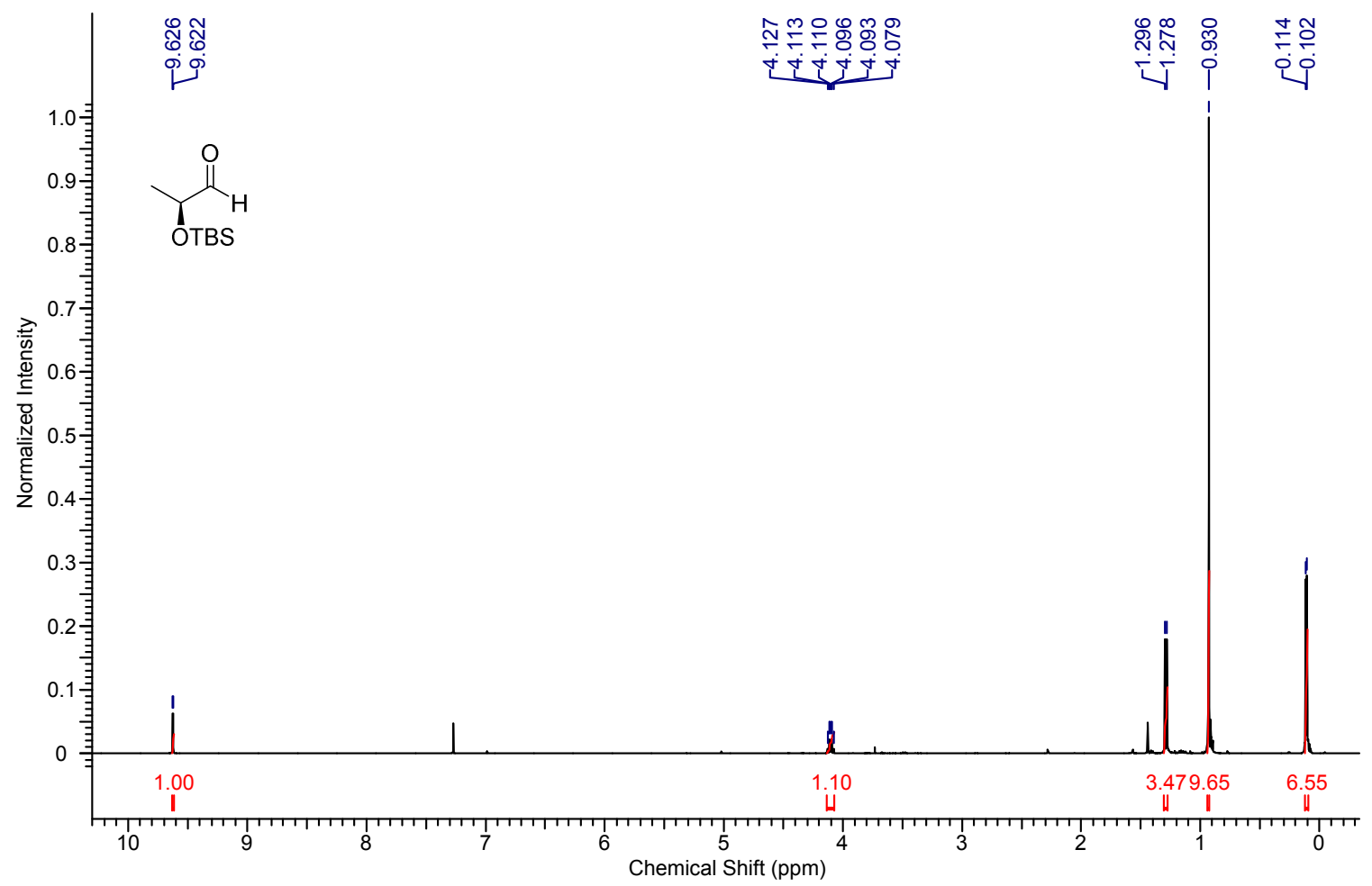




\section{Molecule S1}

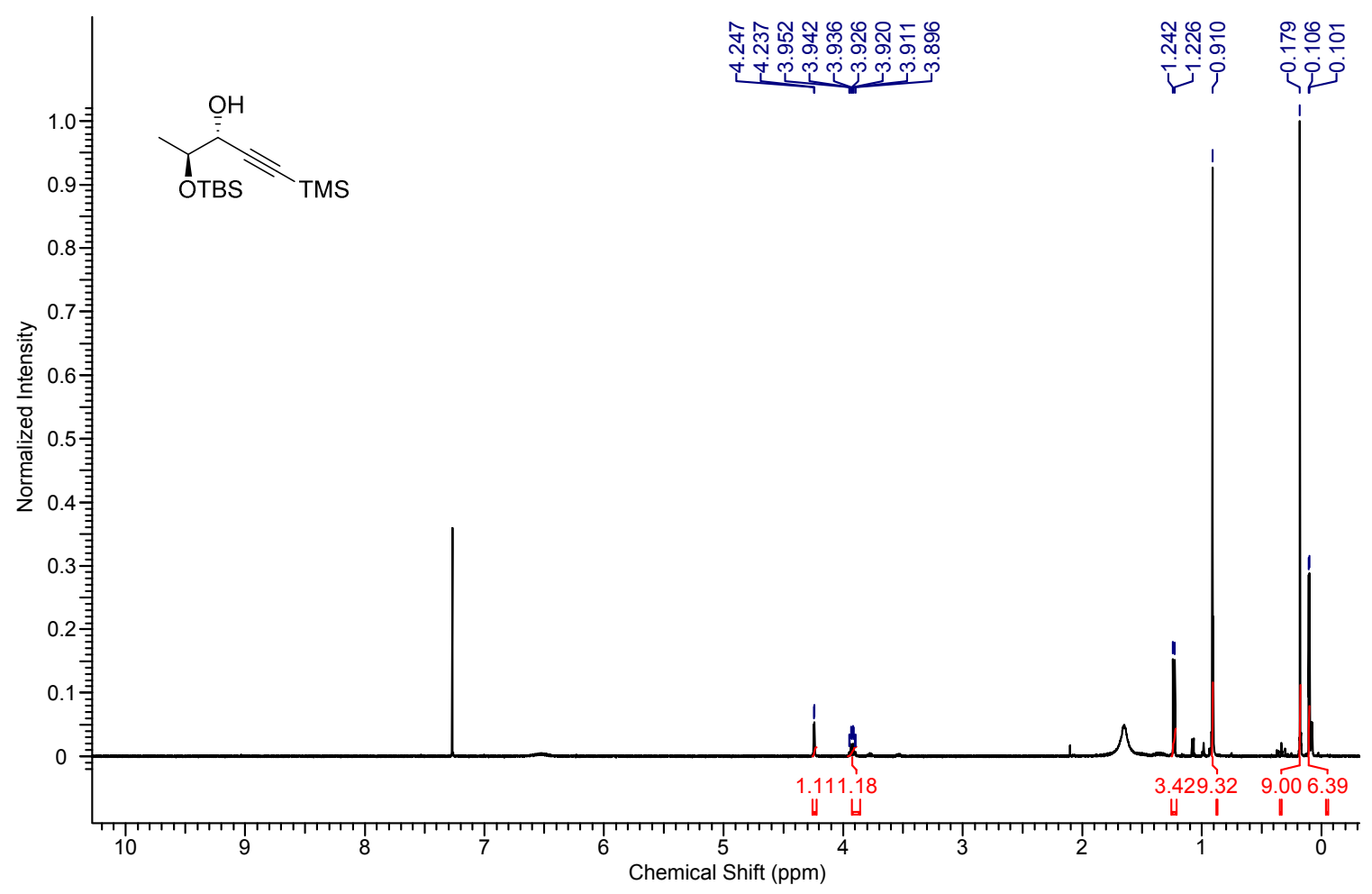

\section{Molecule 7}

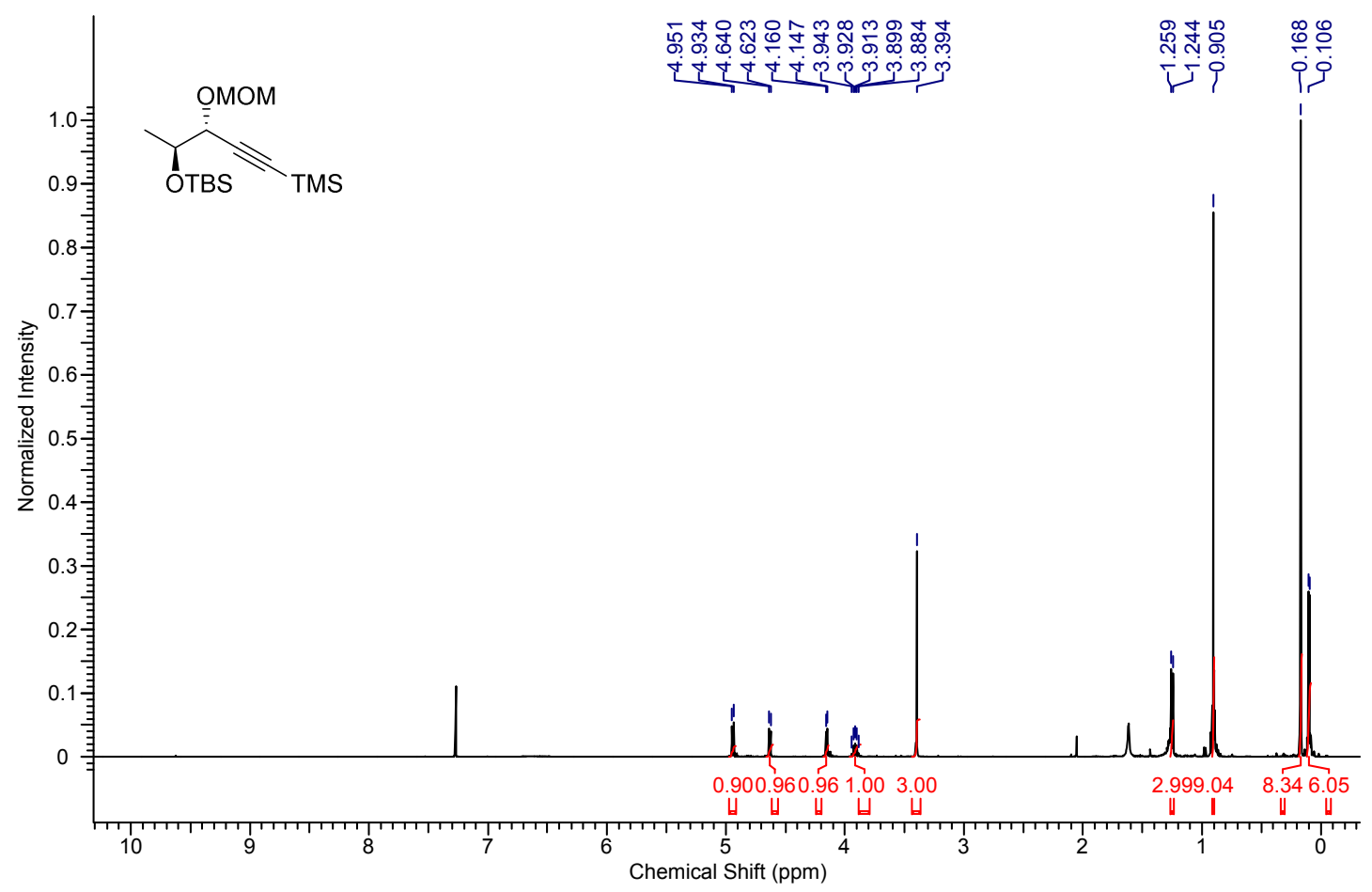




\section{Molecule 10}

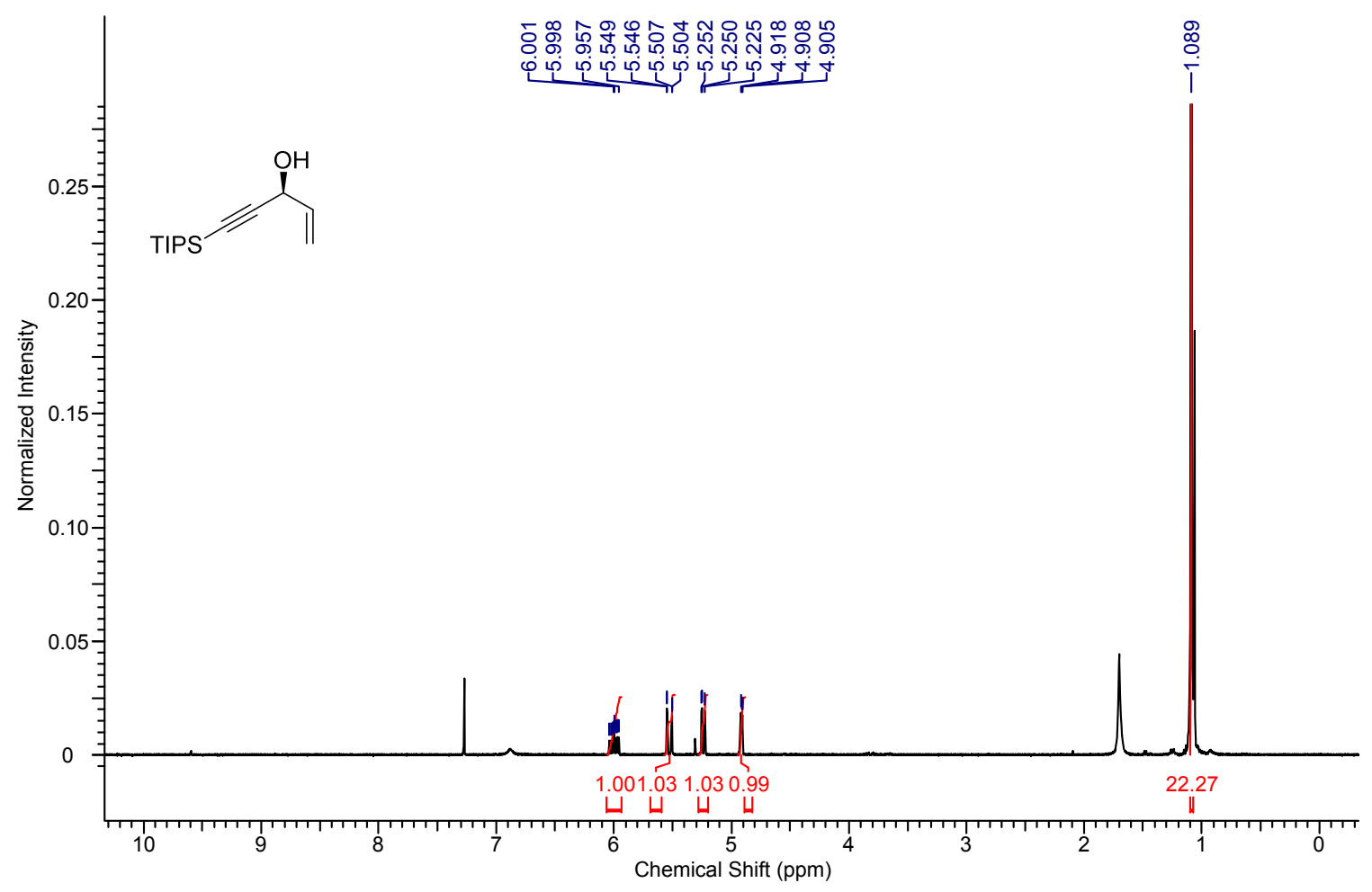




\section{SPECTRAL DATA FOR NEW COMPOUNDS}

\section{MOLECULE 3}
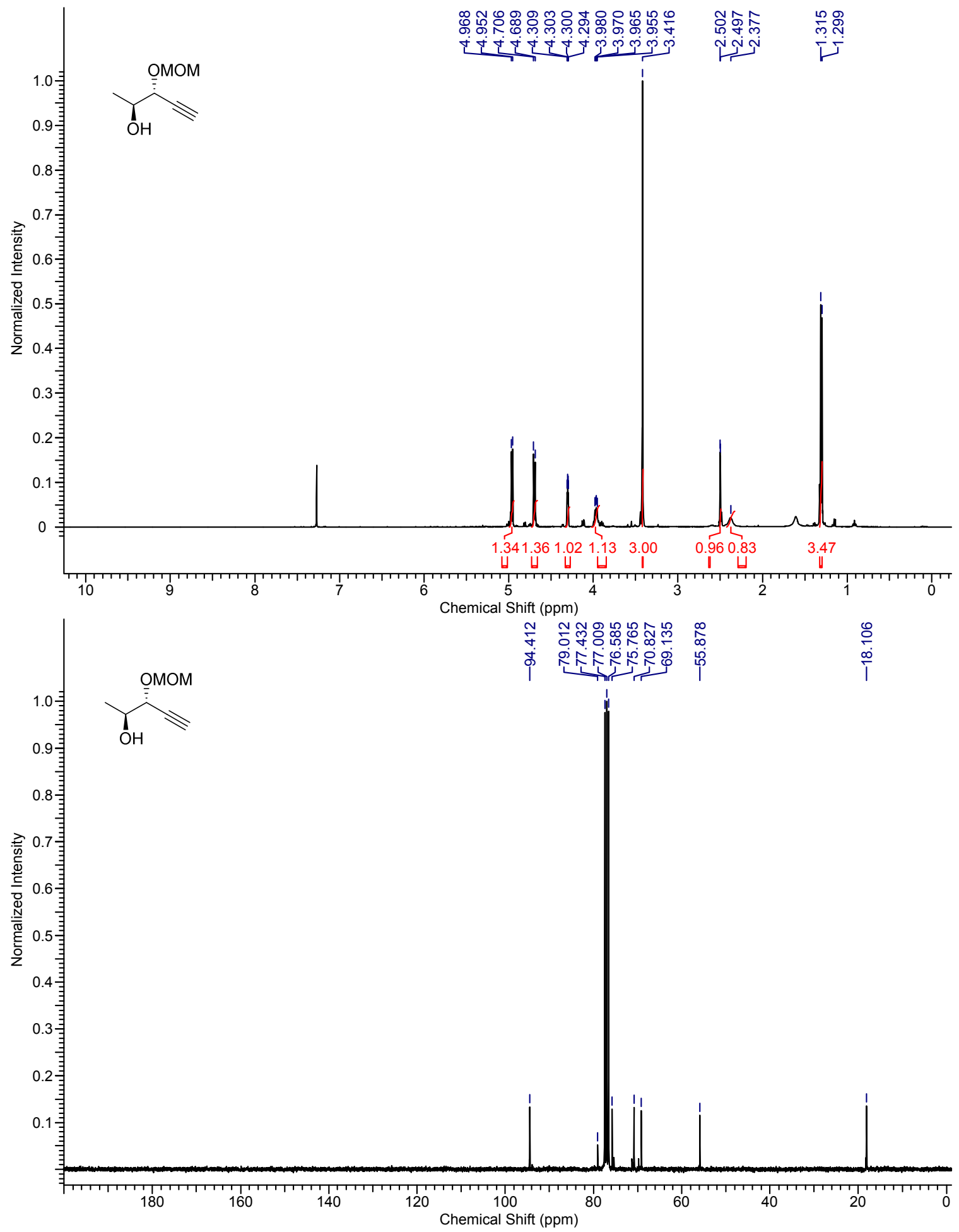


\section{MOLECULE 2a}
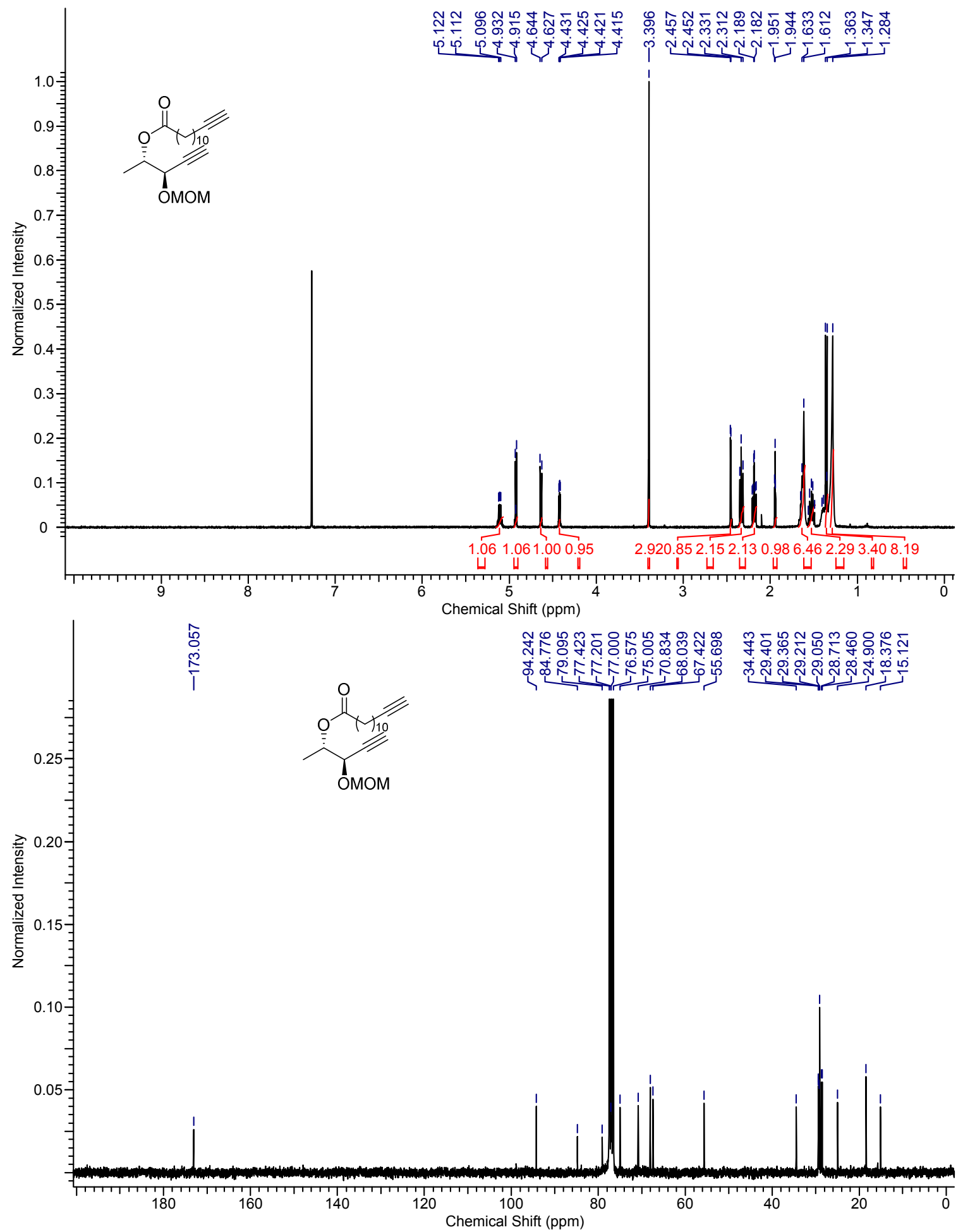


\section{MOLECULE S2}
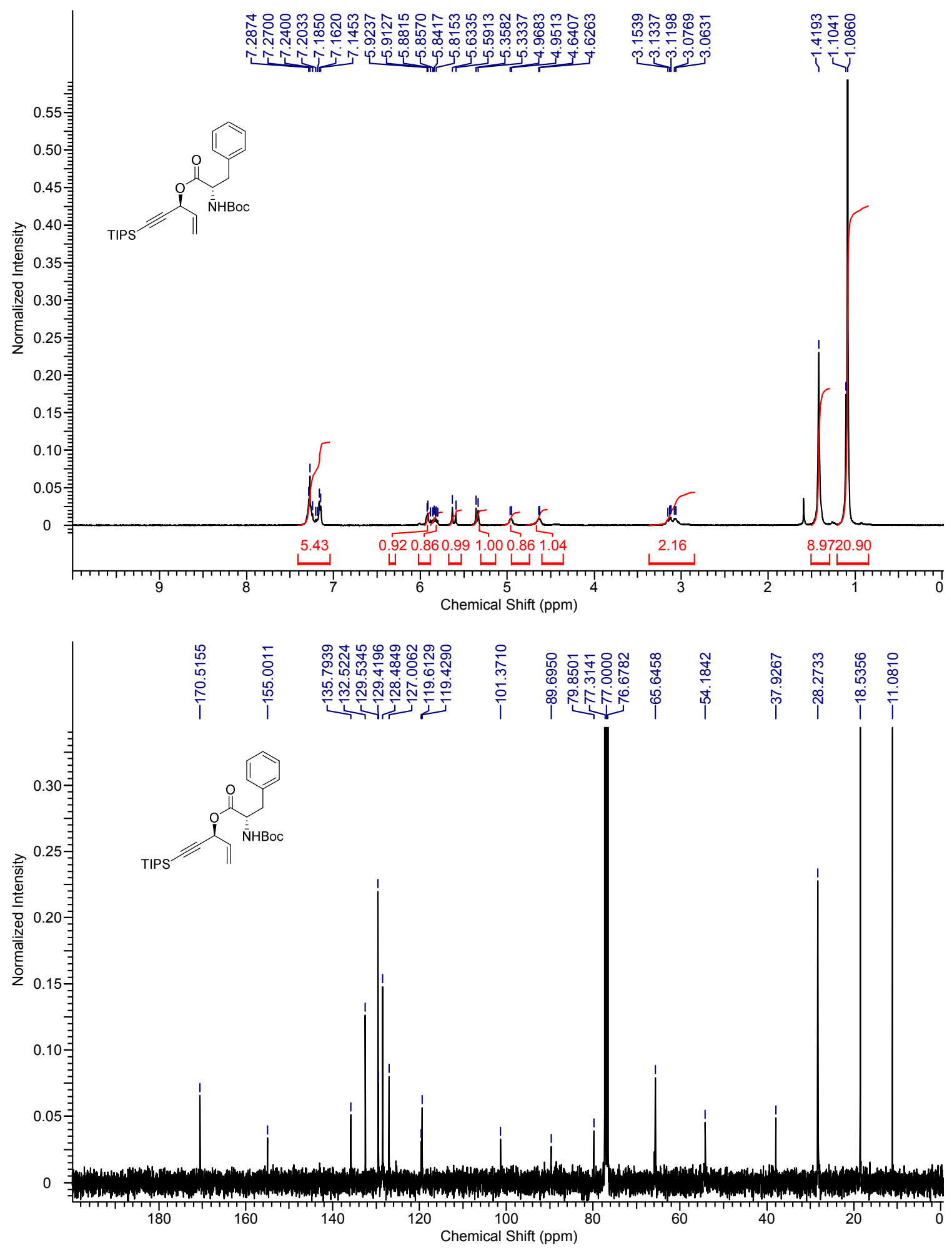


\section{MOLECULE 11}
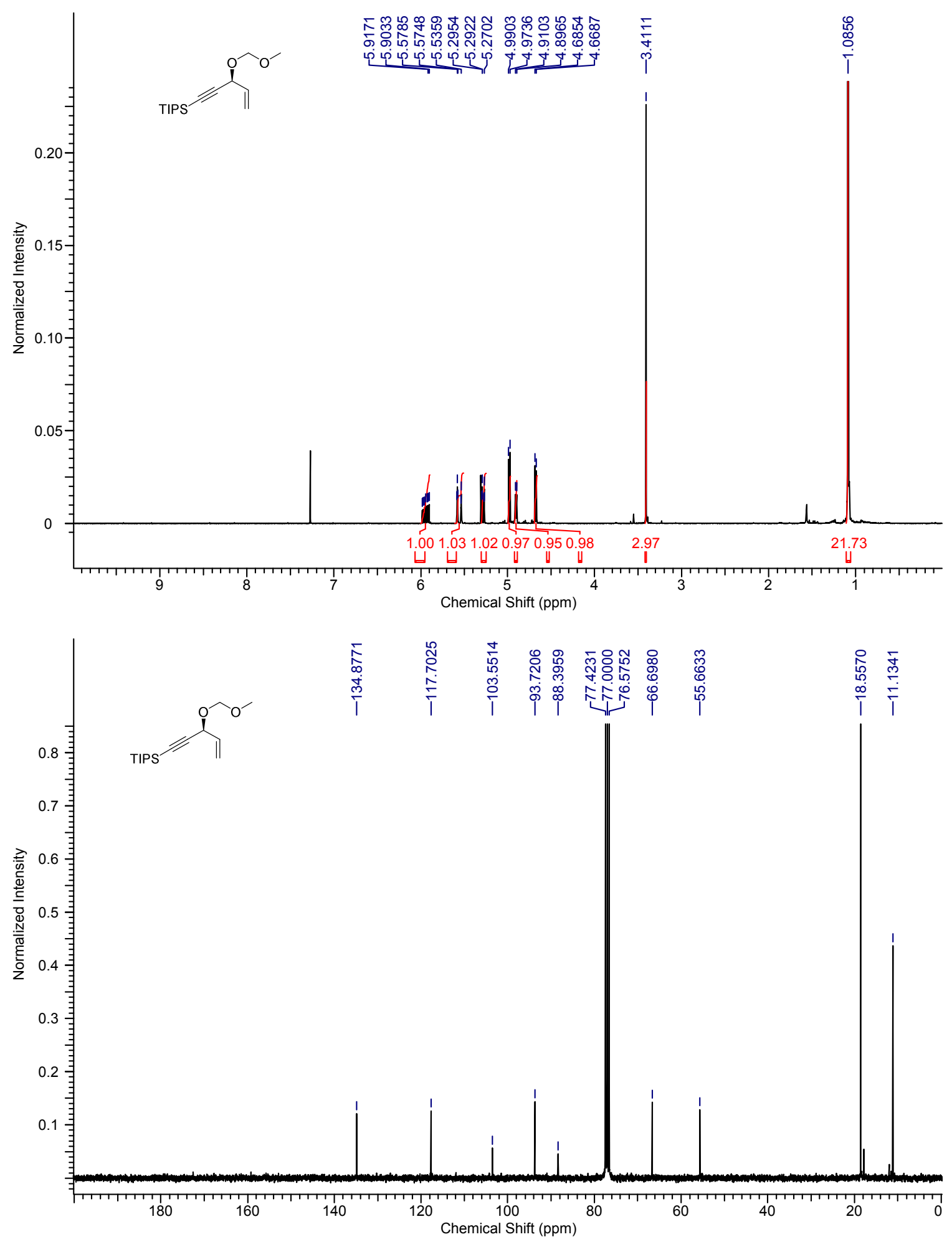


\section{MOLECULE 13}
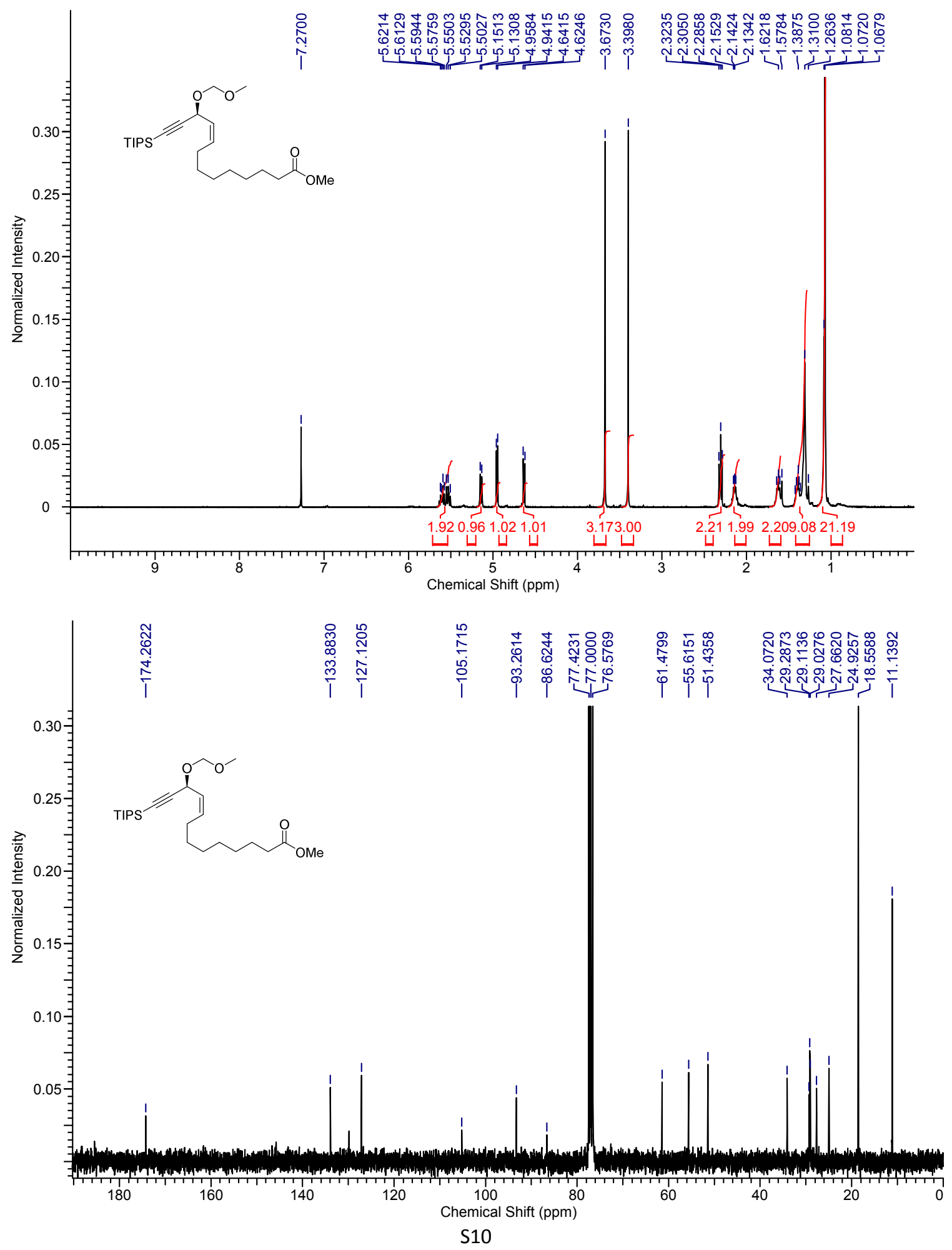


\section{MOLECULE S3}
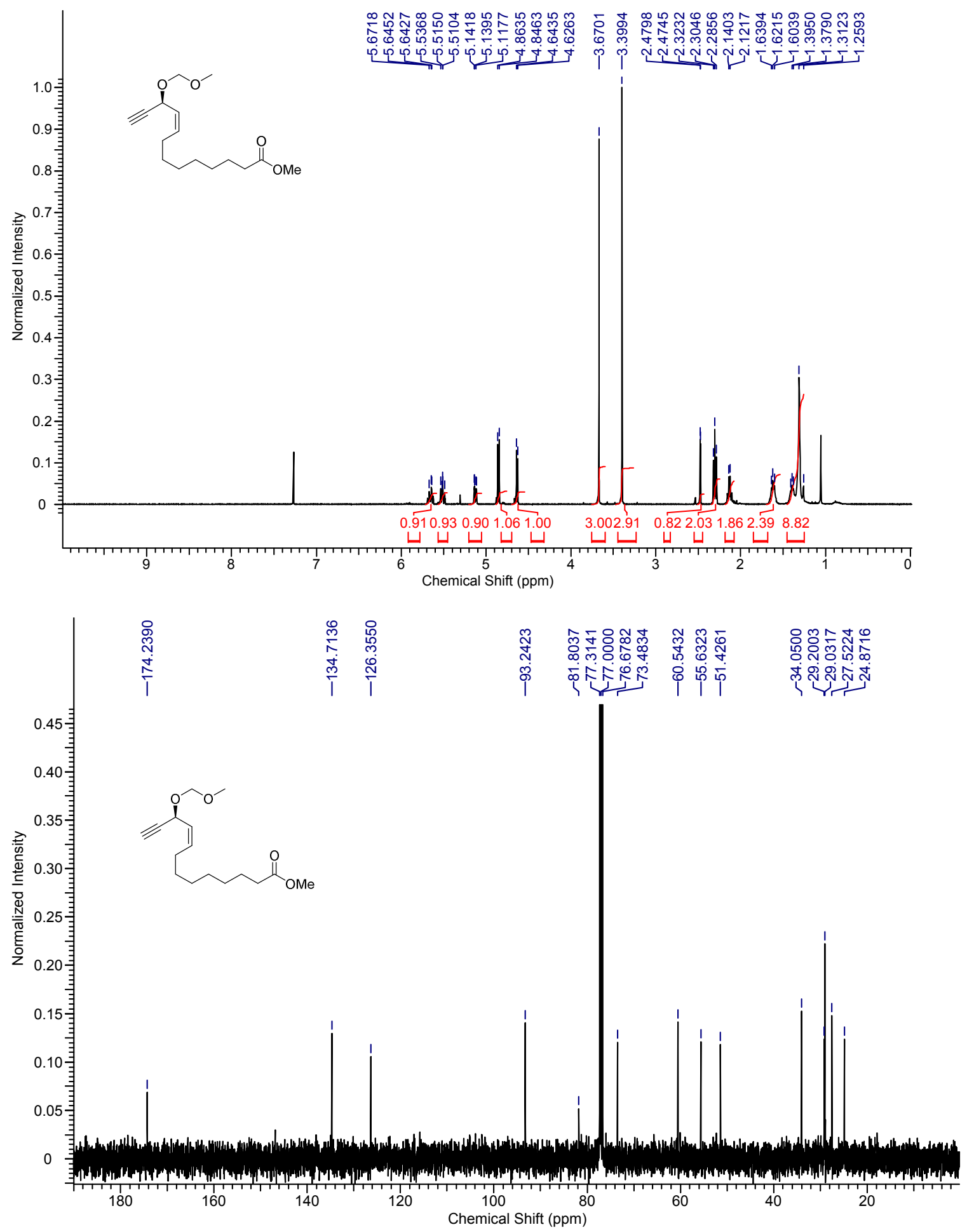
MOLECULE 16
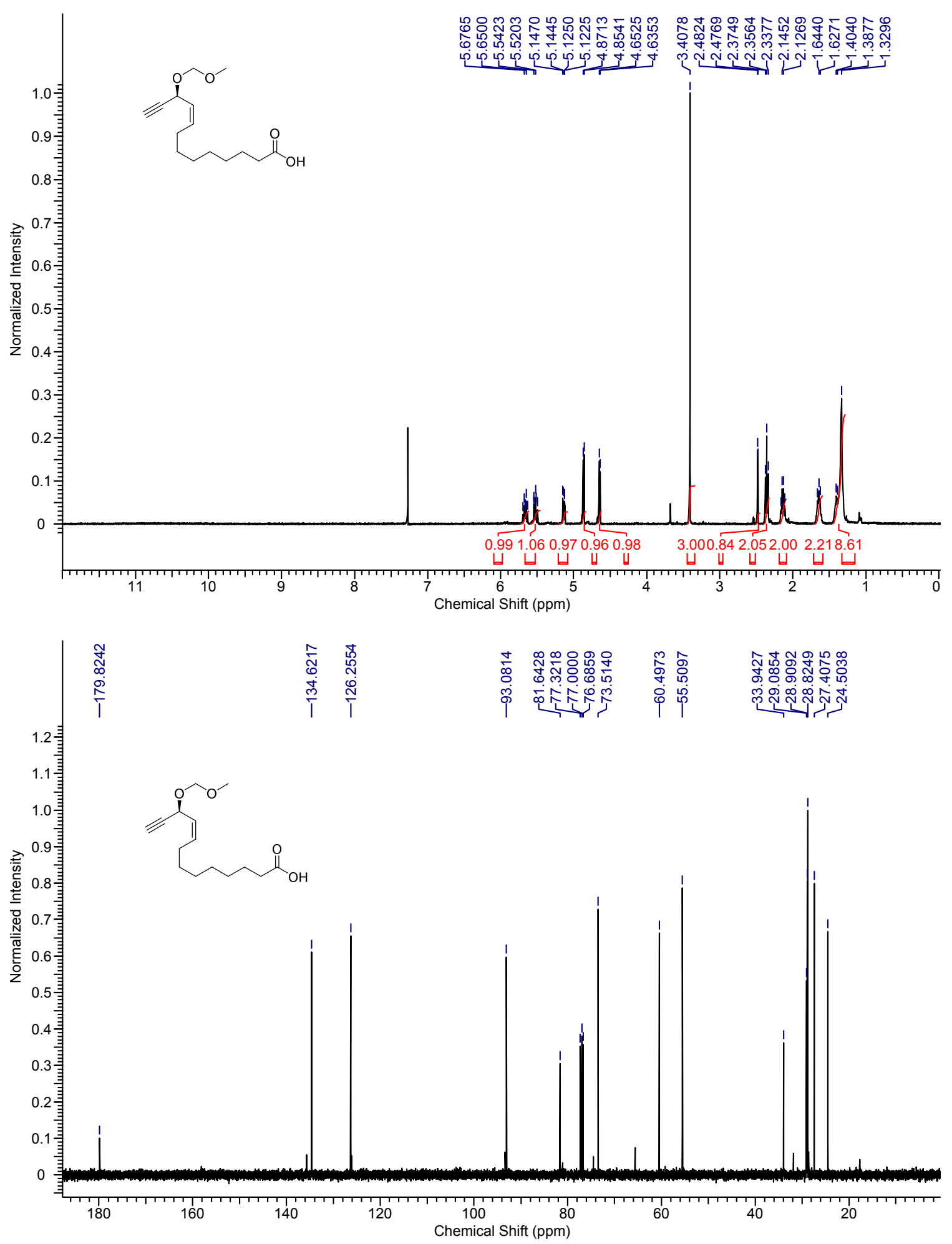

S12 


\section{MOLECULE 2}
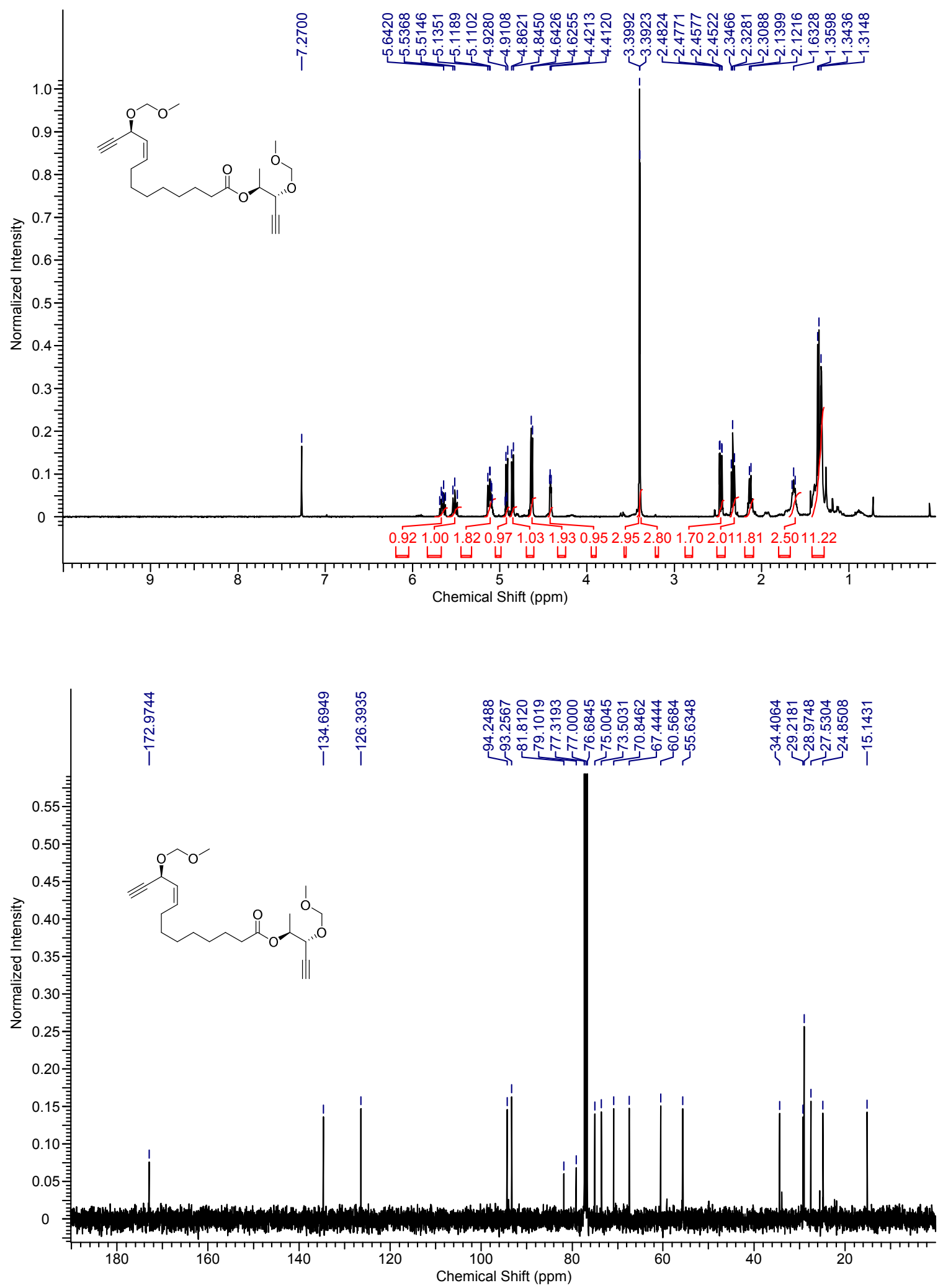


\section{MOLECULE 1}
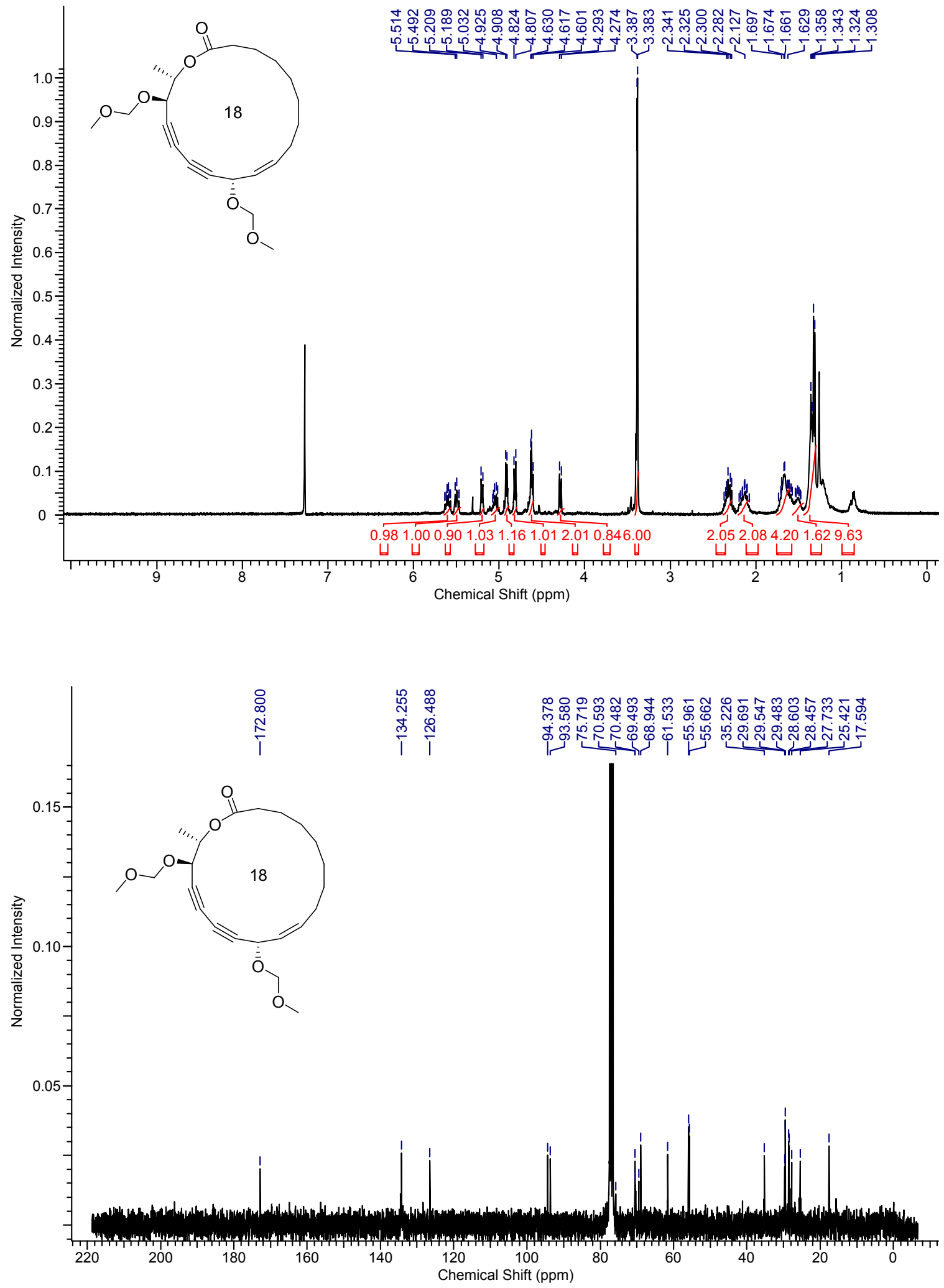


\section{MOLECULE 1a}
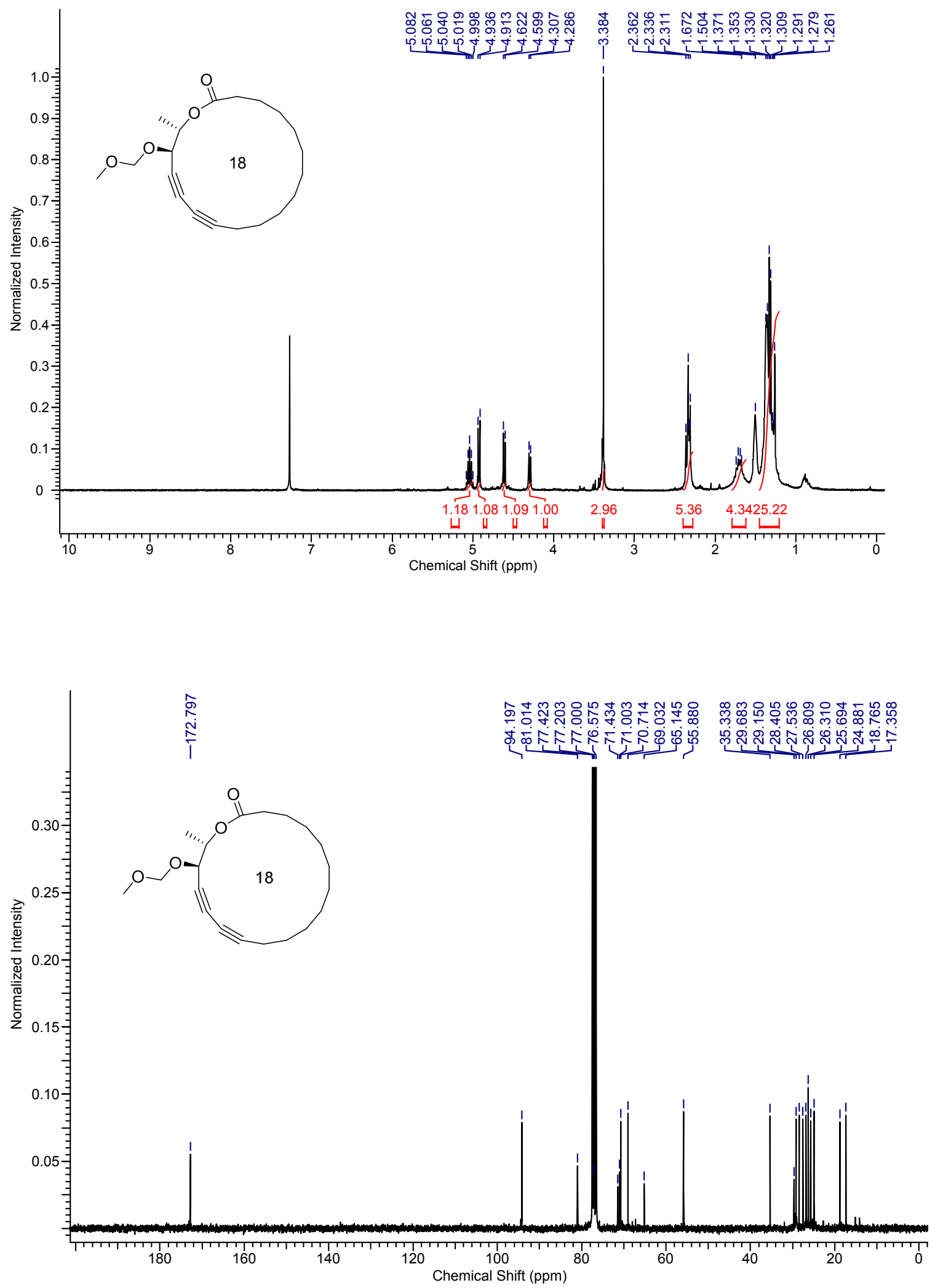